\title{
H.B. Fuller builds new research and development centre
}

$\mathrm{H}$

.B. Fuller has held a ground-break-

ing ceremony for a new research and development centre to be built at the company location "An der Roten Bleiche" in Lüneburg. This will be a complex made up of three sections and covering an area of 2,300 square metres: the western section will house offices and development laboratories; the central section will include a staff canteen, meeting rooms and building services; and the eastern section is to serve as a Customer Centre in which tests, demonstrations and training will be conducted using the very latest equipment. "Our capabilities in Germany are critical to H.B. Fuller's growth strategy," said Jim Owens, president and CEO, H.B. Fuller. "We are committed to growth around
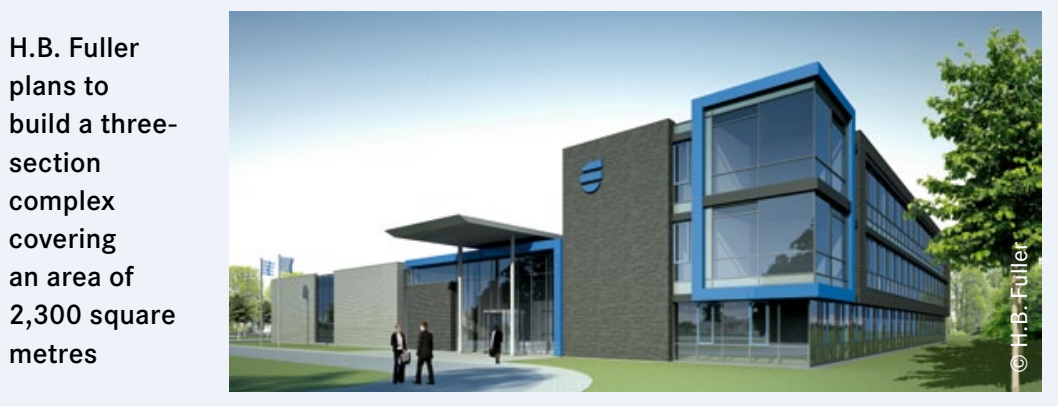

the world, and with the construction of this world-class Technical Centre, we are strengthening our hub in Lüneburg and taking another step forward in the transformation of our European business." The expansion plans form part of a wider business transformation pro- ject designed to streamline and modernise operations throughout the EIMEA region, facilitate profitable growth and ensure that the company is able to provide an even better service to customers. .

Completion of the building is expected for late summer/autumn 2014.

\section{New study of the global butadiene market}

A new market study conducted by the market research company

Ceresana analyses the global butadiene market. Among other things,

it forecasts the development of demand, revenues and production

of this preliminary product - which is also important for the adhesives

industry - up to 2020.

$\mathrm{B}$ utadiene is used in computers, carpets and other products. However, more than half of the total demand for butadiene is generated by producers of styrene-butadiene rubber (SBR) and polybutadiene (BR). Almost $70 \%$ of these products are processed by the tyre industry, but they are also used in adhesives and sealants.

In 2012, however, there were more and more indications that demand for butadiene was in decline due to slow economic development in downstream industries - especially in the production of tyres. This was reflected in the price for butadiene, which fell considerably in all regions after the end of 2012. According to analysts at Ceresana, this slowdown will only be temporary; the market for butadiene is expected to grow again in the future. In 2020, approx. 13.7 million tonnes of butadiene will be processed by downstream industries.

The study also provides company profiles of the most important manufacturers of butadiene, clearly arranged according to contact data, revenues, profit, product range, production sites and capacities, as well as a summary profile. Detailed profiles of a total of 80 producers are given, including BASF, Braskem, Exxon Mobil, Formosa Plastics, Ineos, JSR, Lotte Chemical, LyondellBasell, Petrobras Argentina, PetroChina, Royal Dutch Shell, Sabic, Sinopec, Total, TPC Group and Zeon.

Further information: www.ceresana.com/de/ Market studies/Chemicals/Butadiene

\section{BASF invests in flooring and waterproofing systems}

ASF plans to build a new Eu-
ropean centre of expertise for its flooring and waterproofing systems at the BASF Coatings $\mathrm{GmbH}$ site in Oldenburg, Germany by the end of 2014. For this purpose, the company is investing in the production and development of polyurethane and epoxy-based systems for performance flooring and waterproofing together with logistics, R\&D, sales and service. The investment is the next step in the development of these businesses following the sale of the Conica Sports Surfaces business line and the Swiss Schaffhausen location on July 1, 2013. 